\title{
ENZIMAS AMILOLÍTICAS DE MANDIOQUINHA-SALSA (Arracacia xanthorrhiza Bancroft.) ${ }^{1}$
}

\author{
Tatiana da Costa Raposo PIRES², Erika Matos da VEIGA², Flávio FINARDI FILHO ${ }^{2, *}$
}

\section{RESUMO}

O objetivo do presente trabalho foi de caracterizar as enzimas amiloliticas de mandioquinha-salsa (Arracacia xanthorrhiza Bancroft.). Foram realizados ensaios mediante a determinação da atividade enzimática, variando-se as condições do meio, tais como temperatura, pH e concentração de cátions. Em gel de eletroforese foram detectadas três bandas protéicas com intensa atividade hidrolitica. As enzimas apresentaram pH ótimo de atividade em torno de 6,0 e mostraram-se mais sensiveis a valores de pH alcalino quando préincubadas a 50oC. A temperatura ótima de ativação enzimática foi de 50oC, enquanto aos $700 \mathrm{C}$, a atividade amilásica foi reduzida em $80 \%$. Em temperaturas altas temperaturas (60 e 70oC), a inativação enzimática ocorreu após 60 e 25 min de incubação, respectivamente. Ensaios de estabilidade térmica mostraram que as amilases mantiveram alta atividade após $25 \mathrm{~h}$ mediante a incubação a 20 e 30 oC. Os valores de $\mathrm{Km}$, Vmax e energia de ativação foram de $0,41 \mathrm{mg} / \mathrm{mL}, 1,11 \mathrm{mg} / \mathrm{mL} / \mathrm{min}$ e $7,53 \mathrm{kcal} / \mathrm{mol}$, respectivamente. Constatou-se que a presença de $\mathrm{Ca}+2$ ou $\mathrm{Mg}+2$ provoca aumento na atividade amilásica, enquanto íons de Cu+2 causam uma diminuição. Apesar da discreta atividade amilásica apresentada, as enzimas demonstraram ter alta resistência e estabilidade térmicas.

Palavras-chave: mandioquinha; batata-baroa; Arracacia xanthorriza; alfa-amilase; beta-amilase; caracterização enzimática.

\section{SUMMARY}

AMYLOLYTIC ENZYMES FROM PERUVIAN CARROT (Arracaia xanthorrhiza Bancroft.). This investigation was undertaken to characterize amylases from Peruvian carrot (Arracacia xanthorrhiza Bancroft.). Activity assays were performed in different changing pHs, temperatures, time and cation concentrations. PAGE zymograms and the amylase activity essays were detected by starch-iodine complex. The results showed that Peruvian carrot has three amylase components on the crude extract. The enzymes had optimum $\mathrm{pH}$ at 6.0. Amylases were more sensitive to basic $\mathrm{pH}$ when the pre-incubation occured at $50 \mathrm{oC}$. The best activation temperature occurred at $50 \mathrm{oC}$, whereas at $70 \mathrm{oC}$ the amylase activity was reduced by $80 \%$. Assays of thermal stability at 20 and $30 \mathrm{oC}$ showed that amylases could maintain high activity following 25 hours of exposure at those temperatures. At higher temperatures, 60 and $700 \mathrm{C}$, enzymatic inactivation occurred after 60 and 25 minutes, respectively. Km, Vmax and activation energy value were $0.41 \mathrm{mg} / \mathrm{mL}, 1.11 \mathrm{mg} / \mathrm{mL} / \mathrm{min}$ and $7.53 \mathrm{kcal} / \mathrm{mol}$, respectively. The presence of $\mathrm{Ca}+2$ or $\mathrm{Mg}+2$ ions increased the amylase activity whereas $\mathrm{Cu}+2$ decreased it. In spite of the rather low amylase activity detected, the enzymes showed high resistance and thermal stability.

Keywords: peruvian carrot; Arracacia xanthorriza; alpha-amylase; beta-amylase; enzyme characterization.

\section{1 - INTRODUÇÃO}

A mandioquinha-salsa é originária da região andina da América do Sul, compreendida por Venezuela, Equador, Peru, Bolivia e sobretudo pela Colômbia, local de cultivo intensivo e extensivo, onde se encontra a maior diversidade de plantas da espécie. No Brasil, a mandioquinha-salsa, também conhecida como batata baroa, foi introduzida por volta de 1900, trazida das Antilhas [5], sendo cultivada e consumida nas regiões Sudeste e Sul. Para fins alimentícios são utilizadas apenas as raízes da planta, desprezando-se as porções aéreas, compostas por ramas e pelo pedúnculo. Caracteriza-se como alimento energético apresentando $25 \mathrm{~g}$, em média, de carboidratos totais por $100 \mathrm{~g}$ de raiz [11], sendo largamente empregada em formulações de alimentos infantis, em sopas e em purês.

A conservação da mandioquinha-salsa é um ponto critico na comercialização das raizes [2]. Comparativamente ao ciclo de produção da planta, que varia entre 10 a 11 meses, as raizes possuem curta vida pós-colheita, cuja duração máxima é de 7 dias à temperatura ambiente. Este fato tem implicações diretas no manuseio,

Recebido para publicação em 27/06/2001. Aceito para publicação em 26/02/2002

2. Departamento de Alimentos e Nutrição Experimental da Faculdade de Ciências Farmacêuticas da Universidade de São Paulo - USP.

* A quem a correspondência deve ser enviada. na distribuição e na disponibilização do produto, fazendo com que os preços sofram flutuações acentuadas ao longo do ano $[9,11,12]$.

Os mecanismos de deterioração pós-colheita da mandioquinha ainda não foram suficientemente elucidados. Sabe-se, entretanto, que a lavagem das raizes acelera o processo de deterioração, resultando em perda acentuada de textura e desenvolvimento de bolores nas extremidades; este mecanismo de deterioração pode ser retardado pela manutenção das raizes sob refrigeração, porém acarreta custos adicionais sem a eliminação efetiva do problema. Uma hipótese para explicar esta via de deterioração seria a hidrólise enzimática de carboidratos e o conseqüente fornecimento de açúcar para o crescimento microbiano.

A ação de enzimas amiloliticas na mandioquinha ainda não é conhecida, ao contrário de outros tubérculos, similares a ela em relação ao alto teor de amido em sua composição, como a mandioca [10], a batata [7] e a batata-doce [8], e tampouco há estudos de qualquer outra participação enzimática na deterioração destas raizes. A exemplo de outros organismos, o passo inicial no estudo de amilases é a caracterização bioquímica das enzimas através de parâmetros cinéticos como $\mathrm{K}_{\mathrm{m}}, \mathrm{V}_{\text {máx }}, \mathrm{pH}$ ótimo e temperaturas de ativação e de desnaturação [4, 10, $14,16,17,18]$. No presente trabalho, o objetivo foi caracterizar as enzimas amiloliticas de mandioquinha-salsa em termos de temperatura e pH ótimos e de estabili- 
dade, determinação de parâmetros cinéticos, bem como de estudar a influência de ions sob diversas condições de meio de reação.

\section{2 - MATERIAL E MÉTODOS}

\section{1 - Material}

Raizes de mandioquinha-salsa (Arracacia xanthorrhiza Bancroft. cv Amarelo comum), colhidas no mesmo dia, provenientes da região de São Bento do Sapucaí (SP), não lavadas, constituíram o material para análise. As raizes foram embaladas em sacos de polietileno e armazenadas sob congelamento $\left(-18^{\circ} \mathrm{C}\right)$ até a sua utilização.

Diversos reagentes, como amido de batata, EDTA, Coomassie, acrilamida, fosfato de sódio, foram adquiridos da empresa Sigma Co. Os demais reagentes de uso comum em laboratório eram de grau analítico.

\section{2 - Métodos}

\subsection{1 - Extrato enzimático}

As raizes de mandioquinha-salsa depois de descongeladas, foram lavadas para a remoção de terra e impurezas e imediatamente trituradas. Após a remoção da casca, a raiz foi cortada em pequenos cubos $( \pm 2,0 \mathrm{~cm}$ de aresta); rotineiramente cerca de $250 \mathrm{~g}$ de amostra foram homogeneizados com $100 \mathrm{~mL}$ de água destilada em liquidificador comum. O homogenato foi, então, filtrado e centrifugado a $13.000 \times \mathrm{g}$ por $30 \mathrm{~min}$ a $4^{\circ} \mathrm{C} \mathrm{e}$, em segui$\mathrm{da}$, dialisado contra água à temperatura de $4^{\circ} \mathrm{C}$ por um período minimo de $12 \mathrm{~h}$. A amostra foi armazenada em tubos Eppendorf de $1,5 \mathrm{~mL}$, a temperatura de $-18^{\circ} \mathrm{C}$ até a sua utilização; os tubos foram descongelados conforme a necessidade para execução dos ensaios.

\subsection{2 - Determinação do teor de proteínas}

As proteinas foram quantificadas pelo método descrito por BRADFORD [3] usando a albumina sérica bovina (BSA) como padrão.

\subsection{3 - Determinação da atividade amilásica total}

Para a detecção da atividade amilásica, foi empregado o método da medida do complexo amido-iodo [15] que consiste na mistura do extrato enzimático em solução de $0,1 \%$ de amido de batata, em tampão fosfato $\mathrm{pH} 6,9$, $20 \mathrm{mM}$, seguida de interrupção da reação através da adição de solução de iodo $\mathrm{I}_{2} 10 \mathrm{mM}$ e KI $14 \mathrm{mM}$. Uma unidade de atividade amilásica (U) foi definida como sendo a quantidade de amido (em nanogramas) hidrolisada por minuto por miligrama de proteína presente no extrato enzimático.

Efeito da temperatura - A temperatura ótima de atividade amilásica foi determinada através da incubação do extrato enzimático em diferentes temperaturas (de 25 a $70^{\circ} \mathrm{C}$ ), na presença de substrato, durante 15 min. A temperatura ótima de atividade enzimática foi descrita como a temperatura na qual houve a maior diminuição da intensidade de cor do complexo amido-iodo.

Para a determinação da estabilidade térmica, o extrato enzimático foi pré-incubado em diferentes temperaturas (de 20 a $70^{\circ} \mathrm{C}$ ), na presença de substrato, variando-se também os intervalos de tempo. A atividade amilásica residual foi determinada a $37^{\circ} \mathrm{C}$, por $15 \mathrm{~min}$, a $\mathrm{pH}$ 6,9.

Efeito do pH - No ensaio para a avaliação do $\mathrm{pH}$ ótimo de atividade, o extrato enzimático foi incubado em diferentes soluções tamponadas: entre $\mathrm{pH}$ 3,7 e 5,5 foi utilizado tampão acetato $0,2 \mathrm{M}$; entre $\mathrm{pH}$ 6,0 e 8,0, tampão fosfato 0,2M; entre pH 8,0 e 10,0, tampão de ácido bórico-cloreto de potássio 0,1M. Em todas as soluções acima foi adicionado o substrato, seguindo-se uma incubação por $15 \mathrm{~min}$, a $37^{\circ} \mathrm{C}$. A avaliação do efeito do $\mathrm{pH}$ sobre a estabilidade amilásica foi realizada através de pré-incubação do extrato enzimático em diferentes valores de $\mathrm{pH}$ (de 4,0 a 10,0$)$, durante $15 \mathrm{~min}$ a 5 e $50^{\circ} \mathrm{C}$. Em seguida foi determinada a atividade amilásica residual, a $50^{\circ} \mathrm{C}$, por $15 \mathrm{~min}$, a $\mathrm{pH} 6,9$.

Efeito de ions - Para verificar o efeito da presença de cátions na atividade amilásica, o extrato enzimático foi pré-incubado a 50 e $70^{\circ} \mathrm{C}$, por $15 \mathrm{~min}$. Em seguida, foi determinada a atividade amilásica na presença de ions $\mathrm{Ca}^{+2}, \mathrm{Mg}^{+2}, \mathrm{Mn}^{+2}, \mathrm{Cu}^{+2}$ e de EDTA. O EDTA foi usado na concentração final de $2,5 \mathrm{mM}$. Os cátions utilizados foram adicionados através de soluções de $\mathrm{CaCl}_{2}, \mathrm{MgCl}_{2}$, $\mathrm{MnCl}_{2}$ e $\mathrm{CuSO}_{4}$ nas concentrações de $0,2 \mathrm{mM}, 0,2 \mathrm{mM}$, $2,5 \mathrm{mM}$ e $1,0 \mathrm{mM}$, respectivamente. Para a obtenção de valores de referência, os mesmos ensaios foram realizados sem a incubação prévia do extrato enzimático a 50 ou $70^{\circ} \mathrm{C}$.

Parâmetros cinéticos - Para a determinação da energia de ativação catalisada pela enzima, foi construído o gráfico de Arrhenius considerando as temperaturas de 25 a $70^{\circ} \mathrm{C}$. A curva foi traçada entre os valores de temperatura de 25 a $50^{\circ} \mathrm{C}$, onde ocorrem valores crescentes de atividade enzimática. $\mathrm{O}$ valor da $\mathrm{E}_{\mathrm{a}}$, foi calculado pela tangente da curva. O gráfico de MichaelisMenten foi obtido através da variação da concentração de substrato $(0,05$ a $0,30 \mathrm{mg} / \mathrm{mL})$. Os valores de $\mathrm{K}_{\mathrm{m}} \mathrm{e}$ $\mathrm{V}_{\text {máx }}$ foram calculados a partir do ponto que intercepta o eixo 1/S e 1/V no gráfico de Lineweaver-Burk.

Eletroforese - Foi utilizada a eletroforese não desnaturante em gel de poliacrilamida, descrita por FINARDI-FILHO e LAJOLO [6], para a identificação das bandas de atividade amilásica bem como para a revelação de proteínas do extrato, através da revelação com Coomassie brilhante blue R.

\section{3 - RESULTADOS E DISCUSSÃo}

\section{1 - Temperatura}

Os resultados do ensaio de temperatura ótima de atividade amilásica do extrato de mandioquinha (Figura 1) apresentam um perfil próprio com valor máximo em torno de $50^{\circ} \mathrm{C}$. Em temperaturas superiores a $50^{\circ} \mathrm{C}$, a 
atividade enzimática é bastante reduzida, indicando que a temperatura ótima de ativação enzimática é muito próxima das condições de desnaturação protéica. A 60 e $70^{\circ} \mathrm{C}$, a atividade enzimática é reduzida a aproximadamente 80 e 30\%, respectivamente, em relação à atividade máxima obtida na temperatura ótima. Em outras raizes as temperaturas ótimas obtidas situaram-se em $60^{\circ} \mathrm{C}$ para a mandioca [10] e de $71,5^{\circ} \mathrm{C}$ e $53^{\circ} \mathrm{C}$ para a- e b-amilases de batata-doce, respectivamente [8].

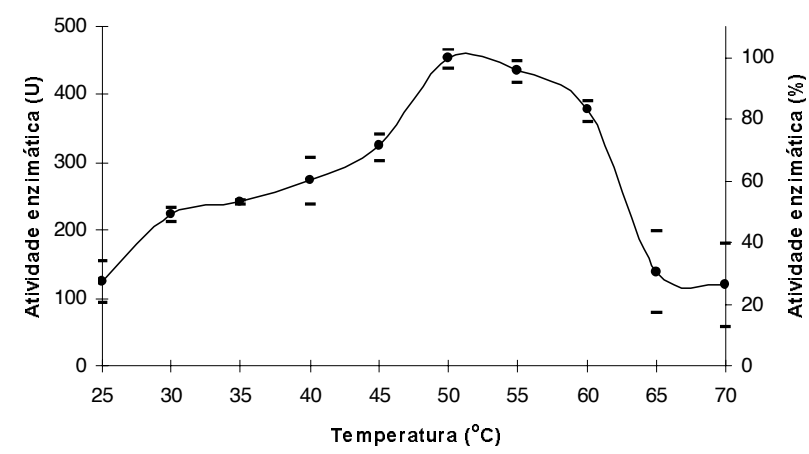

FIGURA 1. Efeito da temperatura na atividade amilásica do extrato de raízes de mandioquinha-salsa: determinação da temperatura ótima de atividade enzimática. O gráfico representa os valores médios de atividade enzimática determinados para cada temperatura, bem como o desvio padrão de cada conjunto de determinações. Uma unidade de atividade enzimática (U) representa quantidade de amido (em nanogramas) hidrolisada por minuto por miligrama de proteína presente no extrato enzimático. A atividade enzimática foi expressa também em atividade enzimática relativa $(\%)$; a $50^{\circ} \mathrm{C}$, o extrato enzimático apresenta-se com atividade máxima (100\%), que corresponde a $451 \mathrm{U}$.

Os ensaios de estabilidade térmica a 20 e $30^{\circ} \mathrm{C}$ demonstraram que as enzimas amiloliticas provenientes de mandioquinha-salsa mantiveram a atividade constante mesmo após $25 \mathrm{~h}$ de incubação nessas temperaturas (Figuras 2 e 3). Quando submetidas a temperaturas de 60 e $70^{\circ} \mathrm{C}$, conforme se pôde inferir anteriormente, a inativação enzimática ocorreu em 60 e $25 \mathrm{~min}$, respectivamente (Figura 2). A $50^{\circ} \mathrm{C}$, temperatura ótima, as amilases mantiveram aproximadamente $60 \%$ de sua atividade inicial mesmo após $5 \mathrm{~h}$ de incubação. A estabilidade do extrato enzimático, medida através da atividade amilásica residual, segue uma tendência linear até a temperatura de $50^{\circ} \mathrm{C}$. Nos ensaios a 20 e $30^{\circ} \mathrm{C}$, nota-se que a atividade enzimática permaneceu estável em até $25 \mathrm{~h}$ de incubação. A mesma linearidade foi observada também a 40 e $50^{\circ} \mathrm{C}$, em até $4 \mathrm{~h}$ de monitoração. Porém, houve perda exponencial de atividade nas temperaturas de 60 e $70^{\circ} \mathrm{C}$ (Figuras 2 e 3).

\section{$3.2-\mathbf{p H}$}

$\mathrm{O}$ efeito da variação do $\mathrm{pH}$ do meio é demonstrado através dos resultados de dois ensaios (Figuras 4 e 5). A Figura 4 mostra que o $\mathrm{pH}$ ótimo para a atividade amilásica encontra-se em torno de 6,0. Em procedimento seme- lhante, o mesmo resultado foi obtido em extratos de mandioca [10]. Em amilases de cereais os valores de $\mathrm{pH}$ de máxima atividade encontram-se entre 5,0 e 6,0 para a-amilase e entre 4,0 e 6,0 para b-amilase [17].

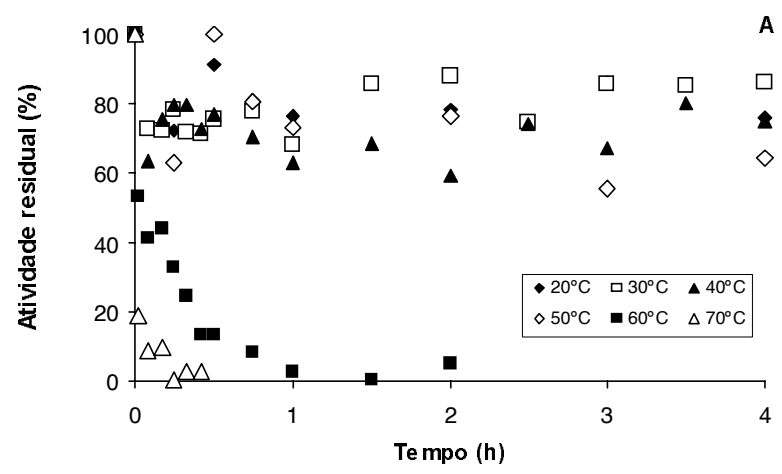

FIGURA 2. Atividade amilásica residual: efeito da temperatura na estabilidade térmica enzimática do extrato de raízes de mandioquinha-salsa em até $4 \mathrm{~h}$ de incubação. A atividade amilásica residual foi determinada após diferentes tempos de exposição, em temperaturas que variaram de 20 a $70^{\circ} \mathrm{C}$. A atividade enzimática foi expressa em atividade enzimática relativa (\%). A $50^{\circ} \mathrm{C}$, após o período de incubação de $30 \mathrm{mi}$ nutos, o extrato enzimático apresentou-se com atividade máxima (100\%), que corresponde a 649 U.

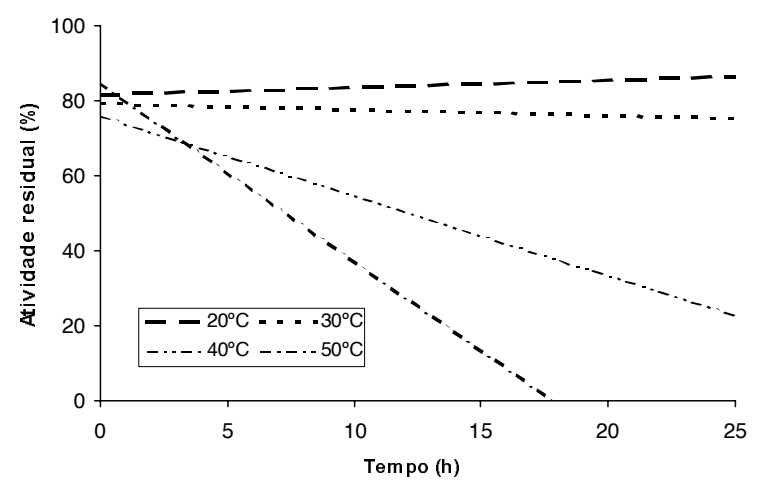

FIGURA 3. Atividade amilásica residual: efeito da temperatura na estabilidade térmica enzimática do extrato de raizes de mandioquinha-salsa em até $25 \mathrm{~h}$ de incubação. A atividade amilásica residual foi determinada após diferentes tempos de exposição, em temperaturas que variaram de 20 a $50^{\circ} \mathrm{C}$. A atividade enzimática foi expressa em atividade enzimática relativa (\%). A $50^{\circ} \mathrm{C}$, após o período de incubação de $30 \mathrm{mi}$ nutos, o extrato enzimático apresenta-se com atividade máxima (100\%) correspondendo a 649 U.

No segundo ensaio, após incubação por $15 \mathrm{~min}$ em duas temperaturas distintas, as enzimas tornaram-se relativamente menos estáveis a pHs alcalinos quando a incubação ocorre a $50^{\circ} \mathrm{C}$ (Figura 5). A temperatura de $5^{\circ} \mathrm{C}$, as amilases demonstraram a capacidade de manter uma alta atividade amilásica em pHs entre 6,0 e 9,0. HAGENINAMA, VÉZINA, SIMARD [8] obtiveram resultados similares para $\alpha$-amilases de batata-doce. Diversos estudos anteriores mostram que $\alpha$-amilases provenien- 
tes de plantas são geralmente estáveis em pHs entre 5,5 e 8,0 [17]. Uma provável explicação para esta diferença de comportamento parece estar relacionada ao grau de ionização das moléculas e às mudanças conformacionais que podem ocorrer na estrutura protéica da enzima em $\mathrm{pH}$ alcalino.

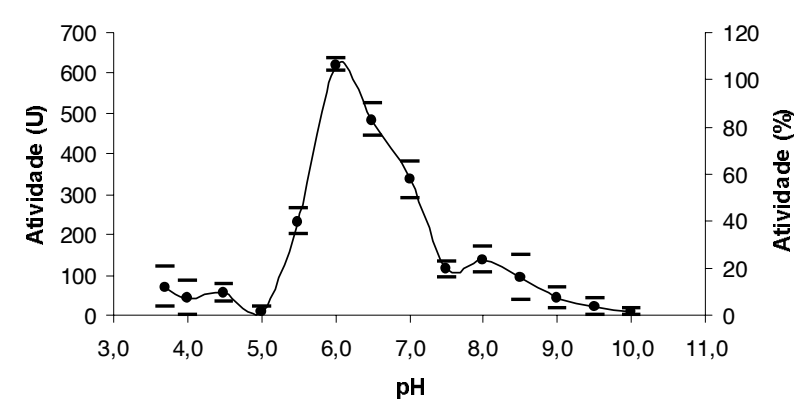

FIGURA 4. Efeito do pH na atividade amilásica do extrato de raízes de mandioquinha-salsa: determinação do $\mathrm{pH}$ ótimo de atividade enzimática. O gráfico representa os valores médios de atividade enzimática determinados para cada $\mathrm{pH}$ e respectivo desvio padrão. Uma unidade de atividade enzimática (U) representa a quantidade de amido (em nanogramas) hidrolisada por minuto por miligrama de proteína presente no extrato enzimático. A atividade enzimática foi expressa, também, em atividade enzimática relativa (\%). A pH 6,0, o extrato enzimático apresenta-se com atividade máxima (100\%), que corresponde a 620 U.

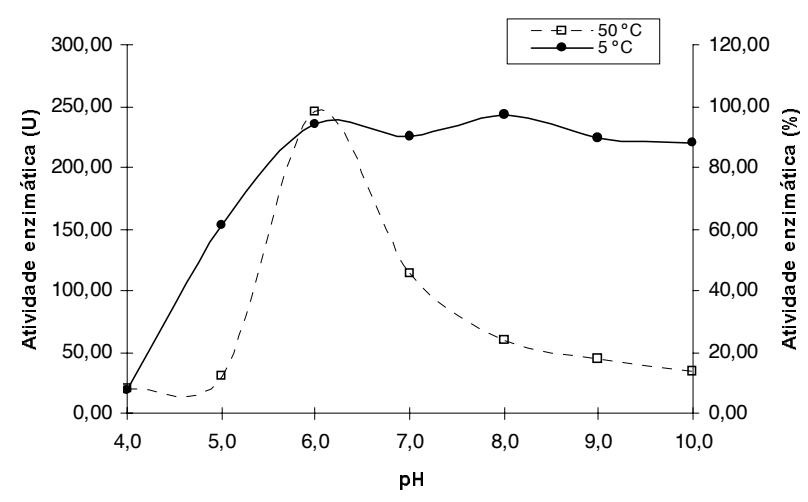

FIGURA 5. Atividade amilásica residual: efeito do pH na estabilidade da atividade enzimática do extrato de raízes de mandioquinha-salsa após pré-incubação do extrato a 5 e $50^{\circ} \mathrm{C}$ por 15 minutos. Uma unidade de atividade enzimática (U) representa quantidade de amido (em nanogramas) hidrolisada por minuto por miligrama de proteína presente no extrato enzimático. A atividade enzimática foi expressa, também, em atividade enzimática relativa (\%). A pH 6,0, após a pré-incubação do extrato enzimático a $50^{\circ} \mathrm{C}$, por 15 minutos, o extrato enzimático apresenta-se com atividade máxima (100\%), que corresponde a $245 \mathrm{U}$.

\section{3 - Presença de íons}

Os resultados apresentados na Tabela 1 indicam que a presença de $\mathrm{CaCl}_{2}$ aumenta a atividade amilásica em
95\% em relação à atividade do extrato enzimático não incubado previamente. A presença de EDTA, quelante de cátions, reduz $53 \%$ da atividade amilásica original, demonstrando que as enzimas são dependentes de $\mathrm{Ca}^{+2}$. A incorporação de $\mathrm{MgCl}_{2}$ ao extrato original também aumenta a atividade amilásica, porém em 34\%. Quando o EDTA é adicionado na presença de $\mathrm{Ca}^{+2}$, a atividade amilásica é reduzida a $73 \%$, enquanto na presença de $\mathrm{Mg}^{+2}$, a atividade é reduzida a $34 \%$ da atividade amilásica original. A adição de $\mathrm{CuSO}_{4}$ diminui a atividade em 39\%. Mediante a adição de $\mathrm{MnCl}_{2}$, praticamente não ocorre alteração na atividade amilâsica, demonstrando que o

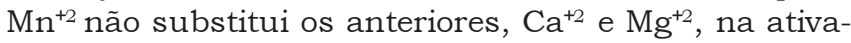
ção da amilase.

TABELA 1. Efeito da adição de íons na atividade amilásica do extrato enzimático de raízes de mandioquinha-salsa mediante a pré-incubação do extrato a 50 e $70^{\circ} \mathrm{C}$, por 15 minutos, e sem pré-incubação deste*

\begin{tabular}{|c|c|c|c|}
\hline \multirow[b]{2}{*}{ Tratamento } & \multicolumn{3}{|c|}{ Atividade enzimática (\%) } \\
\hline & $\begin{array}{c}\text { Sem pré } \\
\text { incubação }\end{array}$ & $\begin{array}{c}50^{\circ} \mathrm{C}, \\
15 \mathrm{~min}\end{array}$ & $\begin{array}{l}70^{\circ} \mathrm{C}, \\
15 \mathrm{~min}\end{array}$ \\
\hline Sem adição de íons & 100 & 95 & 6 \\
\hline $\mathrm{Ca}^{+2}$ & 195 & 152 & 10 \\
\hline $\mathrm{Mg}^{+2}$ & 134 & 96 & 8 \\
\hline EDTA & 47 & 22 & 23 \\
\hline $\mathrm{Ca}^{+2,}$, EDTA & 73 & 24 & 13 \\
\hline $\mathrm{Mg}^{+2}$, EDTA & 34 & 24 & 13 \\
\hline $\mathrm{Mn}^{+2}$ & 98 & 114 & 20 \\
\hline $\mathrm{Cu}^{+2}$ & 39 & 26 & 14 \\
\hline
\end{tabular}

* Sem a pré-incubação do extrato enzimático e sem a adição de ions, o extrato enzimático apresenta-se com atividade enzimática considerada máxima (100\%), que corresponde a $275 \mathrm{U}$.

No ensaio no qual o extrato foi pré-incubado a $50^{\circ} \mathrm{C}$, os resultados indicaram diminuição de somente $5 \%$ da atividade amilásica total. A adição de $\mathrm{Ca}^{+2}$ aumenta a atividade amilásica em $60 \%$ enquanto que a adição de $\mathrm{Mg}^{+2}$ praticamente não resulta em alteração. A adição de EDTA, neste caso, reduz a atividade em $23 \%$. No entanto, não houve alteração significativa quando o EDTA foi

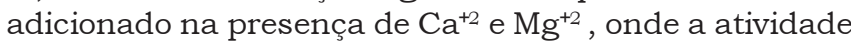
foi reduzida a $25 \%$ em ambos os casos. Esses resultados indicam que, no caso da pré-incubação a $50^{\circ} \mathrm{C}$, a adição de $\mathrm{Ca}^{+2}$ não causa alteração significativa no aumento da atividade amilásica quando em presença de EDTA, ao contrário do que foi observado em ensaios sem pré-incubação do extrato. Estranhamente, apenas nesta condição, a presença de $\mathrm{Mn}^{+2}$ aumentou a atividade amilásica em torno de $15 \%$.

Em todos os casos, a pré-incubação a $70^{\circ} \mathrm{C}$ diminuiu a atividade amilásica. A esta temperatura, grande parte das enzimas presentes no extrato são desnaturadas, com perda da atividade enzimática. Tendo em vista que $\alpha$-amilases provenientes de plantas possuem moléculas de cálcio em sua estrutura [17], os resultados acima confirmam a existência de amilases $\alpha$ e $\beta$ no extrato de mandioquinha-salsa. A presença necessária de $\mathrm{Ca}^{+2}$, 
ou de $\mathrm{Mg}^{+2}$, é indicativo da ação de $\alpha$-amilases e sua remoção com EDTA, com um nivel residual de atividade, pode indicar a ação de $\beta$-amilase, que não necessita de nenhum tipo de metal para a sua ativação [13].

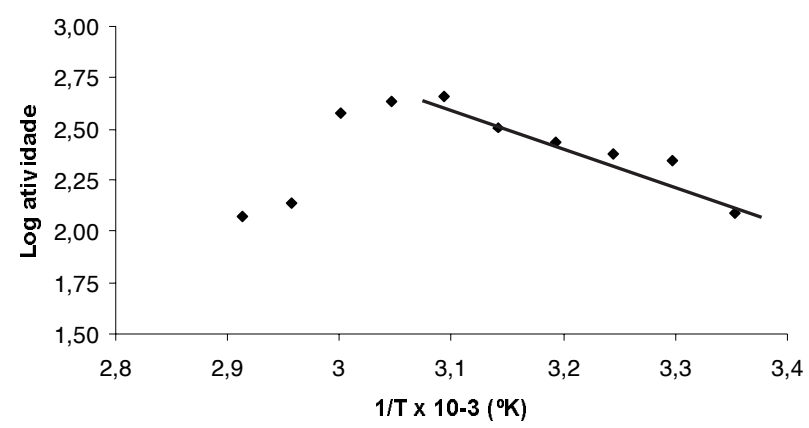

FIGURA 6. Efeito da temperatura na atividade amilásica do extrato enzimático de raízes de mandioquinha-salsa gráfico de Arrhenius. A equação da reta tangente: $\mathrm{y}=-1,8574 \mathrm{x}+8,3844 ; \mathrm{R} 2=0,9169$.

Alguns metais pesados têm mostrado poder de inibição da atividade amilásica, tais como o mercúrio, a prata, o cobre e o chumbo [17]. Nos extratos de mandioquinha $\circ \mathrm{Mn}^{+2}$ parece não afetar a atividade enzimática, exceto quando incubados a $50^{\circ} \mathrm{C}$, enquanto o $\mathrm{Cu}^{+2}$ desestabiliza a enzima mantendo os niveis de atividade semelhantes aos dos tratamentos com EDTA. Estes comportamentos não têm correspondência com enzimas de fontes diferentes. Em $\alpha$-amilase bacteriana, por exemplo, os íons $\mathrm{Mg}^{+2}, \mathrm{Mn}^{+2}$ e $\mathrm{Ca}^{+2}$ no meio de reação não causam alteração nos valores de atividade amilásica, ao passo que a presença de $\mathrm{Cu}^{+2}$ diminui a atividade amilásica em 51\% [13].

HAGENINAMA, VÉZINA, SIMARD [8], trabalhando com batata-doce, utilizaram concentrações mais altas de EDTA, $\mathrm{CaCl}_{2}$ e $\mathrm{MgCl}_{2}(10 \mathrm{mM}, 5 \mathrm{mM}$ e $5 \mathrm{mM}$, respectivamente) em seus experimentos. No presente trabalho, as concentrações destes ions foram adaptadas às condições experimentais para evitar a interferência do iodo utilizado na detecção de atividade enzimática. Para amilases de batata-doce, a presença de $\mathrm{CaCl}_{2}$ durante a pré-incubação a $70^{\circ} \mathrm{C}$ preservou atividade $\alpha$-amilásica em até $67 \%$, enquanto que a presença de $\mathrm{Mg}^{+2}$ não apresentou ação protetora em $\alpha$-amilases de batata-doce. Quando o agente quelante é adicionado, a atividade $\alpha$-amilásica é reduzida a $19 \%$ [8].

Em relação aos outros íons, AGUILAR et al. [1] realizaram experimentos com amilases de Lactobacillus manihotivorans utilizando $\mathrm{MnCl}_{2} \mathrm{e} \mathrm{CuSO}_{4}$ em concentrações finais de $10 \mathrm{mM}$. Em ambos os trabalhos, os autores obtiveram resultados de organismos com maior atividade amilásica, que tanto poderiam ser explicados pela maior expressão das enzimas quanto pela maior atividade específica, o que justifica o emprego de reagentes menos sensiveis do que o método do iodo/iodeto. Como os cátions $\mathrm{Mn}^{+2}$ e $\mathrm{Cu}^{+2}$ precipitavam nas concentrações utilizadas nos trabalhos acima descritos, foram testadas concentrações mais baixas em ensaios preliminares, sem prejuizo dos efeitos constatados pelos ions.

\section{4 - Energia de ativação}

O valor de Ea obtido através do valor da tangente na reta no gráfico de Arrhenius foi de 7,53 kcal/mol (Figura 6. Calculando a $\mathrm{E}_{\mathrm{a}}$ de a-amilase de batata-doce descrita por HAGENINAMA, VÉZINA, SIMARD [8], o valor obtido foi de, aproximadamente, $8,40 \mathrm{kcal} / \mathrm{mol}$, similar ao obtido no presente trabalho. SWAIN \& DEKKER [16] obtiveram um valor de $\mathrm{E}_{\mathrm{a}}$ de $7,6 \mathrm{kcal} / \mathrm{mol}$.

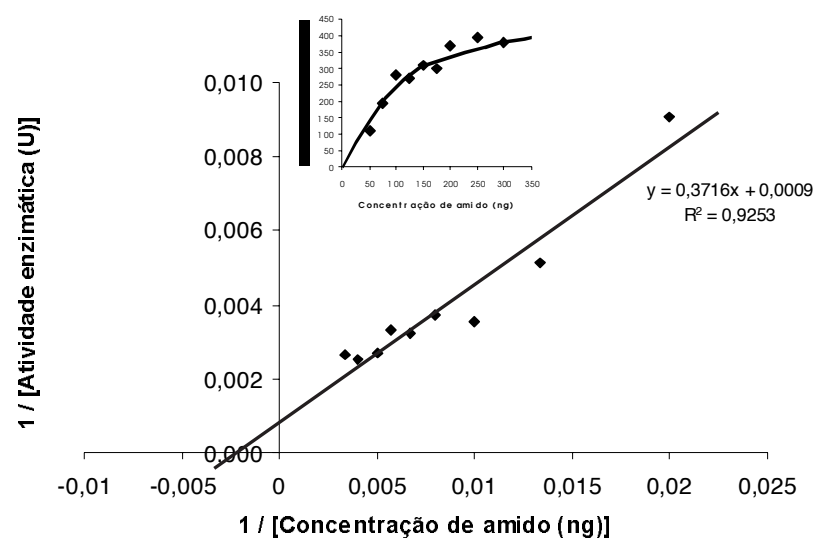

FIGURA 7. Efeito da concentração de substrato na atividade amilásica do extrato enzimático de raízes de mandioquinha-salsa - gráficos de Lineweaver-Burk e Michaelis-Menten (menor).

\section{5 - Determinação de $K_{m}$ e $V_{\max }$}

Os valores de $\mathrm{K}_{\mathrm{m}}$ e $\mathrm{V}_{\max }$ obtidos através do gráfico de Lineweaver-Burk (Figura 7) foram de $0,41 \mathrm{mg} / \mathrm{mL}$ e $1,11 \mathrm{mg} / \mathrm{mL} / \mathrm{min}$, respectivamente. Comparativamente, os valores de $\mathrm{K}_{\mathrm{m}}$ e $\mathrm{V}_{\max }$ encontrados em diversos trabalhos mostram a diversidade de comportamento das enzimas amilásicas. AGUILAR et al. [1] encontraram para a-amilase bacteriana valores de $3,44 \mathrm{mg} / \mathrm{mL}$ e $0,45 \mathrm{mg} / \mathrm{mL} / \mathrm{min}$, respectivamente. HAGENINAMA, VÉZINA, SIMARD [8] obtiveram $\mathrm{K}_{\mathrm{m}}=2,08 \mathrm{mg} / \mathrm{mL} \mathrm{e} \mathrm{V}_{\max }=0,407 \mathrm{mg} / \mathrm{mL} / \mathrm{min}$ para $\alpha$-amilases de batata-doce e de 3,71 mg/mL e 0,969mg/ $\mathrm{mL} / \mathrm{min}$ para $\beta$-amilases. SWAIN \& DEKKER [16] obtiveram um valor de $\mathrm{K}_{\mathrm{m}}$ de $0,2 \mathrm{mg} / \mathrm{mL}$ para $\alpha$-amilases de ervilhas. Os valores de $\mathrm{K}_{\mathrm{m}}$ e $\mathrm{V}_{\max }$ obtidos por outros autores são diferentes dos valores obtidos neste trabalho devido a diversos fatores, como o organismo, fonte da enzima, grau de purificação da amostra, tipo de enzima envolvida e suas características estruturais e físico-químicas. Além disso, todas essas enzimas citadas previamente foram purificadas e concentradas, o que lhes confere, conseqüentemente, valores mais elevados de $\mathrm{K}_{\mathrm{m}}$, sobretudo se as enzimas forem extracelulares, como as de origem bacteriana.

\section{6 - Eletroforese}

Três bandas protéicas com atividade amilolitica foram detectadas em gel de eletroforese no extrato enzimático (Figura 8). Através do deslocamento das ban- 
das observa-se a migração das bandas a e b, de intensidade similar, e de uma banda isolada, c, de atividade menor (ou de menor concentração) do que as anteriores. Pelas características apresentadas é possivel supor que tratam-se de duas $\alpha$-amilases e uma $\beta$-amilase

I II III

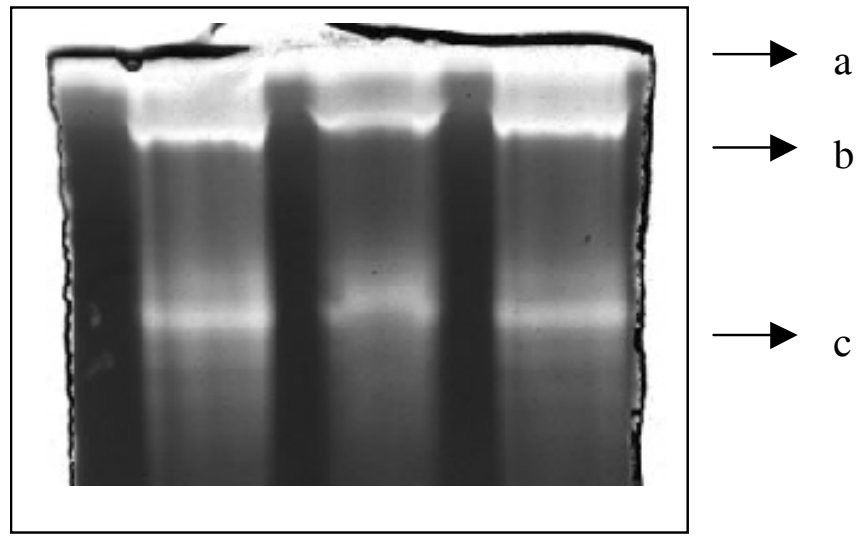

FIGURA 8. Eletroforese nativa em gel de poliacrilamida $25 \%$ e amido a $0,5 \%$, de extrato enzimático de raízes de mandioquinha-salsa. A placa foi pré-incubada em tampão fosfato $\mathrm{pH}$ 6,0 para que fosse feita a revelação com iodo. A figura apresenta três bandas protéicas $(\mathrm{a}, \mathrm{b}$ e c) com atividade hidrolítica sobre o amido. I, II e III representam repetições do mesmo extrato enzimático.

\section{4 - CONCLUSÃO}

Há pelo menos três enzimas amiloliticas ativas no extrato enzimático de mandioquinha-salsa. O extrato enzimático apresentou alta atividade hidrolitica a $50^{\circ} \mathrm{C}$ e pH ótimo em torno de 6,0. Entretanto, a $5^{\circ} \mathrm{C}$, a atividade amilásica mostrou-se tão alta em $\mathrm{pH}$ 6,0 quanto em pH 9,0. A hidrólise do amido pela enzima aumenta na presença de $\mathrm{Ca}^{+2}$ e mantém apenas $20 \%$ da atividade original quando na presença de EDTA. Os resultados indicaram a possivel presença de duas isoformas de aamilase e uma de b-amilase no extrato enzimático in vitro, que poderiam, portanto, também estarem ativas na raiz integra.

As enzimas foram identificadas desta maneira com base nas seguintes informações: 1) a atividade amilásica aumenta na presença de $\mathrm{Ca}^{+2}$ (indicando a atuação de $\alpha$-amilases), porém, na presença do agente quelante EDTA, ainda observa-se atividade remanescente (que pode vir a ser proveniente da $\beta$-amilase); 2) Nos gráficos de temperatura e $\mathrm{pH}$ ótimos, pode-se observar um perfil próprio, com dois máximos presentes nas curvas (no caso da curva de $\mathrm{pH}$ ótimo, nos pHs 6,0 e 8,0 e, no caso da curva de temperatura ótima, a 35 e $50^{\circ} \mathrm{C}$ ), como se houvesse mais de uma forma enzimática atuando no substrato; 3) No gel de eletroforese foram detectadas três bandas protéicas, sendo que duas bem próximas e uma terceira um pouco mais distante, reforçando as evidências de três amilases, duas $\alpha$ e uma $\beta$.

\section{5 - REFERÊNCIAS BIBLIOGRÁFICAS}

[1] AGUilar, G., MORLON-GUYOT, J., TREJO-AGUILAR, B., GUYOT, J.P. Purification and characterization of an extracellular a-amilase produced by Lactobacillus manihotivorans LMG 18010T, an amylolytic lactic acid bacterium. Enzyme and Microbial Technology, v. 27, p. 406-413, 2000.

[2] AVELAR FILHO, J.A. Manejo pós-colheita de Mandioquinhasalsa. Informe Agropecuário, Belo Horizonte, v. 19, n. 190, p. 55-56, 1997.

[3] BRADFORD, M.M. A rapid and sensitive method for the quantification of microgran quantities of protein-dye binding. Analitical Biochemistry, v. 72, p. 248-254, 1976.

[4] DE MOT, R., VERACHTERT, H. Purification and characterization of extracellular a-amilase and glucoamylase from yeast Candida antartica CBS 6678. European Journal of Biochemistry, v. 164, p. 643-654, 1987.

[5] CASALI, V.W.D, SEDIYAMA, M.A.N. Origem e Botânica da Mandioquinha-salsa. Informe Agropecuário, Belo Horizonte, v. 19, n. 190, p. 13-14, 1997.

[6] FINARDI-FILHO, F., LAJOLO, F.M. Identificação eletroforética de $\alpha$-amilase em géis de poliacrilamida-amilopectina. Ciênc. Tecnol. Aliment., v. 2, p. 21-32, 1982.

[7] GORISTEIN, S. Kinetic studies during enzyme hydrolysis of potato and cassava Starches. Starch/Stärke, v. 45, n. 3, p. 91-95, 1993.

[8] HAGENIMANA, V; VÉZINA, L.P; SIMARD, R.E. Sweetpotato $\alpha$ - and $\beta$-amylases: characterization and kinetic studies with endogenous inhibitors. Journal of Food Science, v. 59, n. 2, p. 373-377, 1994.

[9] HENZ, G.P. Métodos de conservação pós-colheita de mandioquinha-salsa. In: Encontro Nacional sobre a mandioquinha-salsa, 5., 1995, Venda Nova do Imigrante, ES. Palestra e Trabalhos Técnicos... Venda Nova do Imigrante: SOB, 1995. p. 21-24.

[10] MATOS da VEIGA, E., PICANÇO MAGALHÃES, C., FINARDIFILHO, F. Isolamento e caracterização inicial de amilases em raizes de mandioca (Manihot suculenta). In: XVII Congresso Brasileiro de Ciência e Tecnologia de Alimentos, vol. 2, p. 5.89 (resumo), 2000.

[11] PEREIRA, A.S. O valor nutritivo da mandioquinha-salsa. In: Encontro Nacional sobre a mandioquinha-salsa, 5., 1995, Venda Nova do Imigrante, ES. Palestra e Trabalhos Técnicos... Venda Nova do Imigrante: SOB, 1995. p. 14-16.

[12] SANTOS, F.F. dos. A cultura da mandioquinha-salsa no Brasil. Informe agropecuário, Belo Horizonte. v. 19, n. 190 , p. 5-7, 1997. Unidades: $\mathrm{CNPH}$

[13] SANTOS, F.F. dos., CARMO, C.A.S. do., VITELA, N.J. Colheita, classificação, embalagem e comercialização. In SANTOS, F.F. dos, CARMO, C.A.S. do, Mandioquinhasalsa: manejo cultural. Brasília: EMBRAPA-SPI/ EMBRAPA-CNPH, 1998. P. 64-79.

[14] SILVANOVICH, M.P., HILL, R.D. a-Amilases from triticale 6A190: purification and characterization. Cereal Chemistry, v. 54, n. 6, p. 1270-1281, 1977.

[15] STREET, H.V. Glycoside hydrolases - amylases: measurement of starch-iodine complex. In BERGMEYER, H. Methods of Enzyme Analyses, vol. 2, second edition, Academic Press, New York, 1974.

[16] SWAIN, R.R., DEKKER, E.E. Purification and properties of an a-amilase from the cotyledons of germinating peas. Bioquimica et Biophysica Acta, v. 122, p. 75-86, 1966. 
[17] THOMA, J.A., SPRADLIN, J.E., DYGERT, S. Plant and animal amylases,. In BOYER, P.D. The Enzymes, 3 rd, Ed. Academic Press, NY, 1959, vol. 5, p. 115-182.

[18] ZHANG, T; OATES, C.G. Relationship between $\alpha$-amylase degradation and physical-chemical properties of sweet potato starches. Food Chemistry, v. 65, p. 157-163, 1999.

\section{6 - AGRADECIMENTOS}

Ao Conselho Nacional de Desenvolvimento Científico e Tecnológico - CNPq, pelo apoio financeiro, e ao Eng Agrônomo Amélio José Bertí, do Núcleo de Produção de Sementes e Mudas da Secretaria da Agricultura de São Bento de Sapucaí, pela doação de raizes de mandioquinha-salsa. 